University of New Hampshire

University of New Hampshire Scholars' Repository

4-2013

\title{
Underwater radiated noise levels of a research icebreaker in the central Arctic Ocean
}

\author{
Ethan H. Roth \\ University of California - San Diego \\ Val E. Schmidt \\ University of New Hampshire, Durham, Val.Schmidt@unh.edu \\ John A. Hildebrand \\ University of New Hampshire, Durham \\ Sean M. Wiggins \\ University of New Hampshire, Durham
}

Follow this and additional works at: https://scholars.unh.edu/ccom

Part of the Oceanography and Atmospheric Sciences and Meteorology Commons

\section{Recommended Citation}

E. H. Roth, V. Schmidt, J. A. Hildebrand, and S. M. Wiggins, 'Underwater radiated noise levels of a research icebreaker in the central arctic ocean', The Journal of the Acoustical Society of America, vol. 133, no. 4, p. $1971,2013$.

This Journal Article is brought to you for free and open access by the Center for Coastal and Ocean Mapping at University of New Hampshire Scholars' Repository. It has been accepted for inclusion in Center for Coastal and Ocean Mapping by an authorized administrator of University of New Hampshire Scholars' Repository. For more information, please contact Scholarly.Communication@unh.edu. 


\title{
Underwater radiated noise levels of a research icebreaker in the central Arctic Ocean
}

\author{
Ethan $\mathrm{H} \mathrm{Roth}^{\text {a) }}$ \\ Scripps Institution of Oceanography, University of California, San Diego, 9500 Gilman Drive, \\ La Jolla, California 92093-0205 \\ Val Schmidt \\ Center for Coastal and Ocean Mapping/Joint Hydrographic Center, University of New Hampshire, \\ Durham, New Hampshire 03824 \\ John A. Hildebrand and Sean M. Wiggins \\ Scripps Institution of Oceanography, University of California, San Diego, 9500 Gilman Drive, \\ La Jolla, California 92093-0205
}

(Received 10 January 2012; revised 21 December 2012; accepted 22 January 2013)

\begin{abstract}
U.S. Coast Guard Cutter Healy's underwater radiated noise signature was characterized in the central Arctic Ocean during different types of ice-breaking operations. Propulsion modes included transit in variable ice cover, breaking heavy ice with backing-and-ramming maneuvers, and dynamic positioning with the bow thruster in operation. Compared to open-water transit, Healy's noise signature increased approximately $10 \mathrm{~dB}$ between $20 \mathrm{~Hz}$ and $2 \mathrm{kHz}$ when breaking ice. The highest noise levels resulted while the ship was engaged in backing-and-ramming maneuvers, owing to cavitation when operating the propellers astern or in opposing directions. In frequency bands centered near 10, 50 , and $100 \mathrm{~Hz}$, source levels reached $190-200 \mathrm{~dB}$ re: $1 \mu \mathrm{Pa}$ at $1 \mathrm{~m}$ (full octave band) during icebreaking operations. (C) 2013 Acoustical Society of America. [http://dx.doi.org/10.1121/1.4790356]
\end{abstract}

PACS number(s): 43.30.Nb, 43.50.Lj, 43.60.Cg [MS]

Pages: 1971-1980

\section{INTRODUCTION}

\section{A. Background}

Icebreakers are designed to operate in ice-covered waters with a strengthened hull, an ice-clearing shape, and the propulsion power to push through consolidated ice. Conventionally powered (i.e., non-nuclear) icebreakers have operated successfully on trans-Arctic voyages in summer as well as on scientific expeditions to high-latitudes in almost all regions of the Arctic Ocean. Although icebreakers represent a relatively small proportion of the total vessel traffic in the Arctic $(\sim 50$ active icebreakers in the world fleet), they are invaluable for surveying, oceanographic research, vessel escort in ice, salvage, pollution response, and search and rescue.

The thinning Arctic ice pack and advances in ship design are allowing for longer seasons of navigation for both icebreakers and other polar-class vessels (Jensen, 2007). Likewise, an increasing number of research icebreakers are conducting geological and geophysical studies throughout the Arctic Ocean related to establishing the limits of an Extended Continental Shelf under the U.N. Convention on the Law of the Sea (Arctic Council, 2009). Icebreaker activity will also increase as mineral and petroleum resources are developed in the offshore region (Jensen, 2007). Seasonal shipping traffic is expected to keep increasing in the near future due to industrial development as well as political and scientific interests in the Arctic region, and the use of polar icebreakers could

\footnotetext{
a) Author to whom correspondence should be addressed. Electronic mail: eroth@hawaii.edu
}

significantly lengthen the shipping season (Arctic Council, 2009). The potential for an expanding presence of icebreakers in the Arctic motivates characterization of their noise signatures to better understand their future contribution to Arctic underwater noise.

Compared to other vessels, icebreakers generate higher and more variable noise levels from propeller cavitation due to the episodic nature of breaking ice, which often involves maneuvers such as backing-and-ramming into the ice. Some icebreakers are equipped with bubbler systems that blow highpressure air into the water to push floating ice away from the ship, creating an additional noise source over short ranges.

Sound propagation under sea ice is an area of acoustics research that is complex due to scattering effects from ice, absorption of acoustic energy at the ice-water interface, and the possibility that shear waves transmitted through ice might re-radiate into the water column (Etter, 2003). Under ice transmission loss is largely unaffected by ice coverage at ranges where direct path propagation is possible. Conversely, transmission loss is greatly affected at distances in which the only propagation path requires at least one water-ice reflection (Milne and Ganton, 1964). Incorporating sea ice conditions, water depth, and sound speed profile may help to model longrange sound propagation in the Arctic Ocean and therefore predict the ranges at which icebreaker noise may be detected.

We present results from in situ shipboard experiments designed to measure underwater sound pressure levels radiated by an icebreaker operating in the Arctic Ocean. While past studies have measured icebreaker noise from stationary locations near shore or on the ice, real-time acoustic monitoring of an icebreaker has not previously been reported for 
the offshore ice-covered waters of the central Arctic Ocean. Received sound pressure levels were recorded at various distances in typical ice-breaking conditions. Source level estimates are reported while making comparisons with various ship operation parameters such as propeller shaft rotations and speed-over-ground.

\section{B. Characteristics of the icebreaker Healy}

U.S. Coast Guard Cutter (USCGC) Healy (WAGB-20) is one of the world's largest non-nuclear polar icebreakers and was designed as a high-latitude platform for conducting a variety of Arctic and sub-Arctic research. The ship is equipped with an automated engineering plant, state-of-the-art navigational equipment, extensive communication and computer systems, a voyage management system, and a modern suite of science systems (Berkson and DuPree, 1998).

Healy was commissioned in August 2000 and has an overall length of $128 \mathrm{~m}(420 \mathrm{ft})$, maximum beam of $25 \mathrm{~m}$ $(82 \mathrm{ft})$, full-load draft of $8.9 \mathrm{~m}(29.2 \mathrm{ft})$, and full-load displacement of 16,400 LT (Berkson and DuPree, 1998). The ship's propulsion is diesel-electric with an ac/ac cycloconverter system. The generating plant consists of four Sultzer (12Z AU40S) main diesel engines, while propulsion power is provided by two fully reversing, variable speed, Westinghouse AC Synchronous drive motors (11.2 MW). The ship's control includes two rudders and two fixed pitch four-bladed propellers with a maximum shaft horsepower of 30000 horsepower (HP) at 130 revolutions per minute (rpm). Healy also has a $2500 \mathrm{HP}$ bow thruster with Alstom dynamic positioning system. There is no bubbler system; a bow-wash system was installed to lubricate the hull during icebreaking, but it is rarely used.

Healy's cruising speed is $12 \mathrm{kn}(6.2 \mathrm{~m} / \mathrm{s})$ at $105 \mathrm{rpm}$ with a maximum speed of $17 \mathrm{kn}(8.7 \mathrm{~m} / \mathrm{s})$ at $147 \mathrm{rpm}$. Its icebreaking capability was designed for breaking through $1.4 \mathrm{~m}(4.5 \mathrm{ft})$ thick ice of $690-\mathrm{kPa}(100-\mathrm{psi})$ strength at $3 \mathrm{kn}$
$(1.5 \mathrm{~m} / \mathrm{s})$ continuous, while actual (best) performance is $1.7 \mathrm{~m}(5.5 \mathrm{ft})$ at $2.6 \mathrm{kn}(1.3 \mathrm{~m} / \mathrm{s})$ continuous. Healy has proven capable of breaking ice up to $2.4 \mathrm{~m}$ ( $8 \mathrm{ft}$ ) thick while backing and ramming. For the purposes of this study, we will consider substantial coverage of ice that is $1.2 \mathrm{~m} \mathrm{(4 \textrm {ft } )}$ thick or greater to present heavy ice breaking conditions. In general, however, the Healy is considered a medium polar icebreaker (O'Rourke, 2012).

In summer 2008, a research expedition (HLY-0805) took place in the central Arctic Ocean to map the seafloor in support of U.S. delineation of an Extended Continental Shelf under provisions of the U.N. Convention on the Law of the Sea (Mayer and Armstrong, 2008). During the HLY-0805 cruise from August 14, 2008 to September 5, 2008, passive acoustic monitoring of USCGC Healy was conducted during ice-breaking operations in the Chukchi and Beaufort Seas. These measurements were taken opportunistically by deploying and tracking omnidirectional sonobuoys on a noninterference basis with the main science objective. An analysis of these recordings was conducted with the goal of estimating radiated underwater acoustic source levels during different modes of propulsion in various sea ice conditions.

\section{MATERIALS AND METHODS}

\section{A. Data collection}

The study was conducted in the western Arctic Ocean while Healy was mapping the seafloor north of the Chukchi Cap (Fig. 1). Typical water depths were between 3 and $4 \mathrm{~km}$ over the "foot" of the continental slope-the area where the continental margin transitions into the deep seafloor. Passive acoustic measurements were made between August 27 and 31, 2008 when Healy's navigation presented opportunities for acoustic studies. A total of nine sonobuoys were deployed during moderate-to-heavy ice breaking and while the ship was stationary during deep-sea dredging operations in water depths exceeding $3 \mathrm{~km}$. Approximately $14 \mathrm{~h}$ of sonobuoy

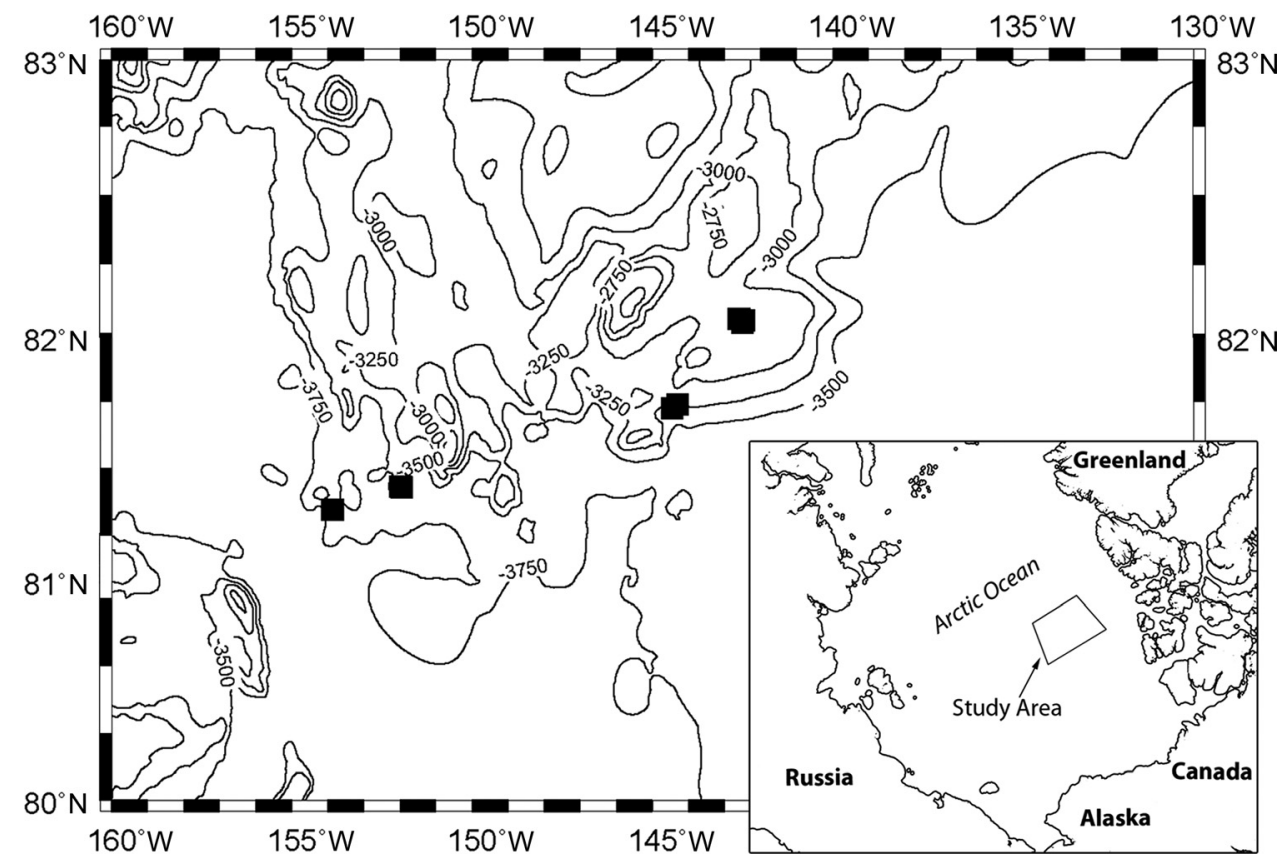

FIG. 1. Bathymetric map of the area for measurements of U.S. Coast Guard Cutter Healy in the deep water $(>3000 \mathrm{~m})$ Arctic Ocean. Sonobuoy deployments are indicated by black squares and the depth contour interval is $250 \mathrm{~m}$. Data provided by the International Bathymetric Chart of the Arctic Ocean (Jakobsson et al., 2008). 

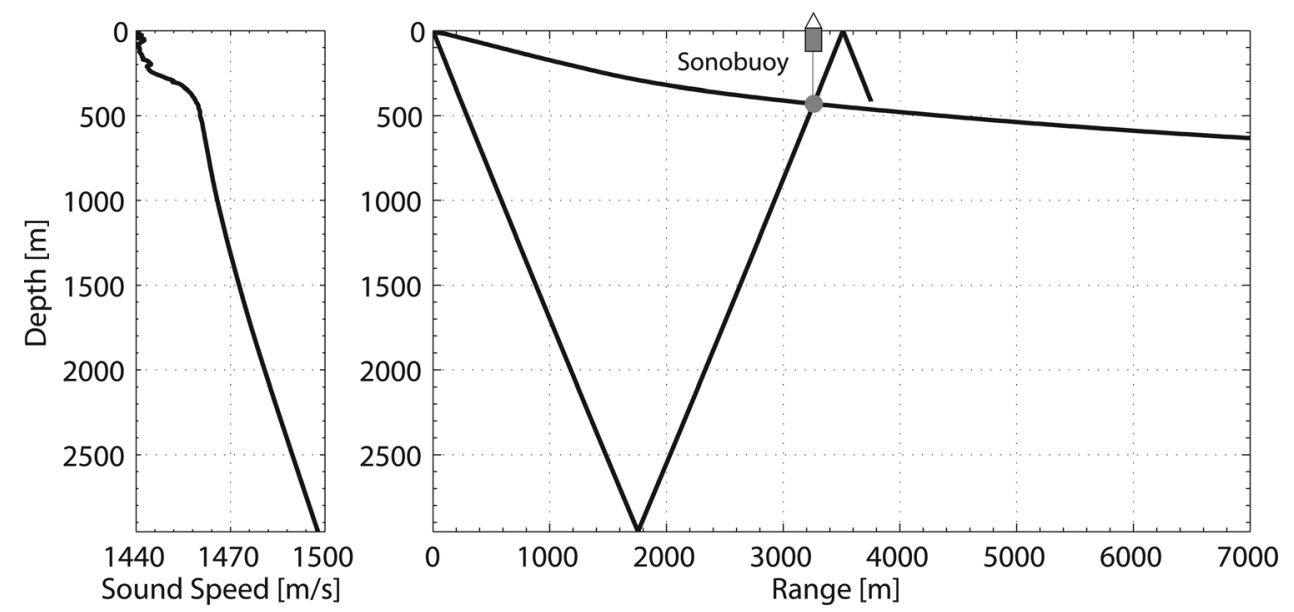

FIG. 2. Sound speed profile (left) and ray path diagram (right) used to estimate launch angles for the bottom-bounce and direct path intersection at the sonobuoy depth. The horizontal range at which this occurs allows derivation of the slant range for transmission loss modeling.

recordings were made. Portions of the sonobuoy recordings in close proximity to the ship were clipped due to high noise levels and were not used for analysis. Although we assume that noise generated by the Healy's propulsion and machinery dominate the radiated noise, the sounds of breaking ice may also be included in our recordings.

\section{B. Acoustic recording equipment}

The Sparton AN/SSQ-57B is a low frequency analysis and recording (LOFAR) sonobuoy that provides omnidirectional passive acoustic data between $10 \mathrm{~Hz}$ and $30 \mathrm{kHz}$. The hydrophone depth was selected to be $122 \mathrm{~m}$ ( $400 \mathrm{ft}$ ) for noise measurements in deep water. A frequency modulated radio signal was transmitted from the sonobuoys' very high frequency (VHF) transmitter at the sea surface to an omnidirectional antenna mounted atop Healy's mast. Signals were passed to an antenna splitter/amplifier, two ICOM R100 frequency modulated (FM) radio receivers, a Sound
Blaster Audigy 2NX analog-to-digital (A/D) converter, and laptop computer. The data were sampled at $48 \mathrm{kHz}$ and recorded using the real-time data acquisition software ISHMAEL (Mellinger, 2001).

Sonobuoys scuttle after $8 \mathrm{~h}$, but more often they would first exceed the transmission range for sufficient VHF reception $(\sim 5 \mathrm{~km})$. Because sonobuoys were not designed for icecovered waters, several deployments failed as the pack ice reconsolidated aft of Healy's stern. The increase in surrounding pressure sometimes caused damage to the surface electronics or hydrophone cable. There were also instances where Healy would reverse direction due to ice conditions, and the sonobuoy was either destroyed or experienced intermittent data loss due to contact with the ship.

\section{Hydrophone calibration}

The Sparton Corporation provides nominal calibration curves for the sonobuoy model used in these measurements.

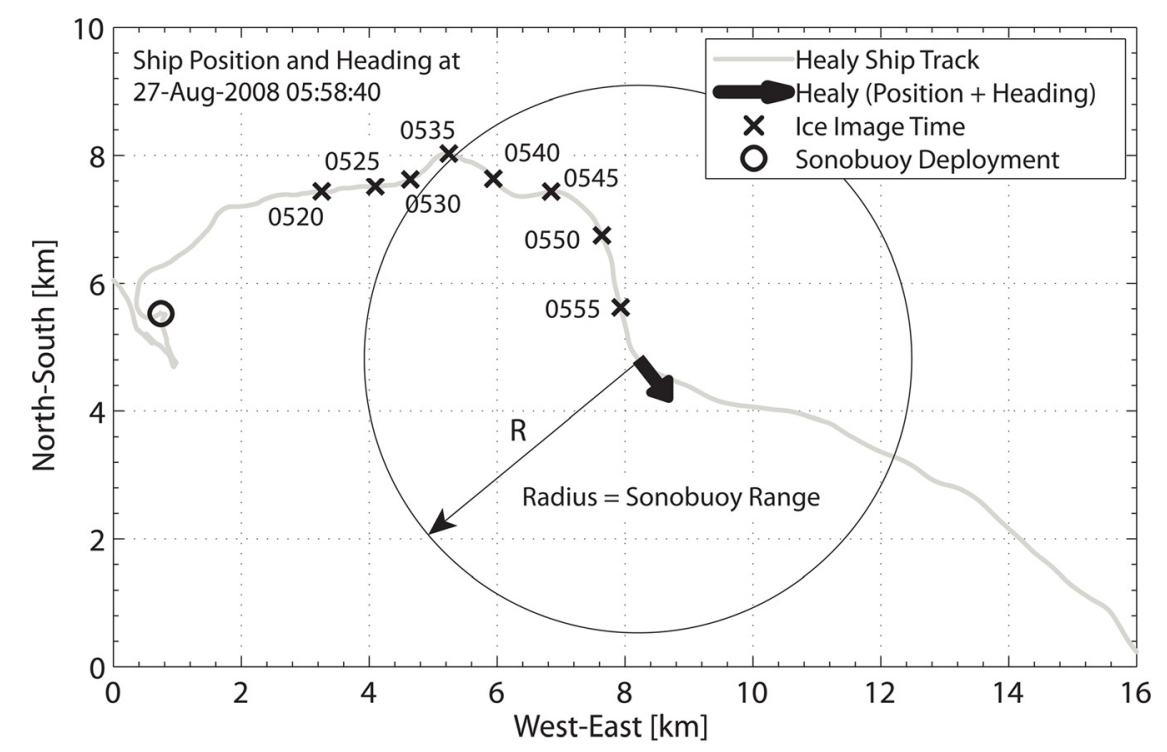

(a)

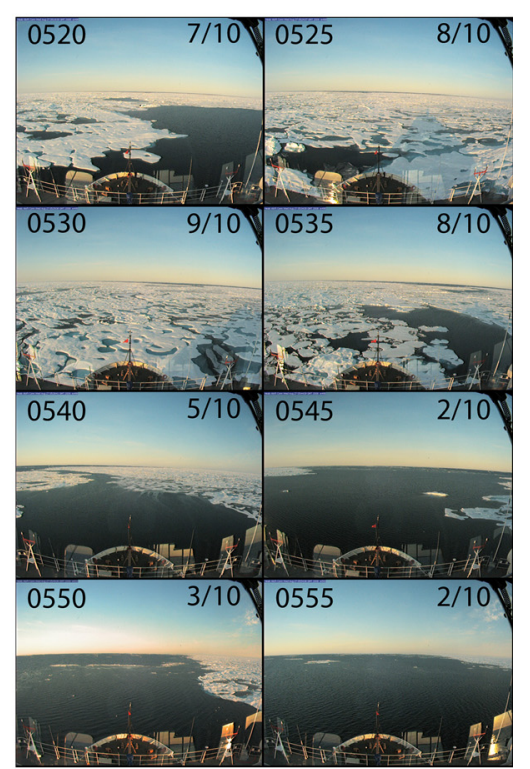

(b)

FIG. 3. (Color online) During transit in variable ice cover on August 27, 2008: (A) Healy's ship track (gray line) relative to the sonobuoy deployment (small black circle), range estimate of the sonobuoy to the ship (large circle), as well as position and heading of Healy at 05:58:40 (arrow). The sonobuoy drifted with speeds over 1 knot $(0.5 \mathrm{~m} / \mathrm{s})$, depending on surface currents, wind, and pack ice dynamics. Coordinate system origin is at $81^{\circ} 42.82^{\prime} \mathrm{N}, 143^{\circ} 59.65^{\prime} \mathrm{W}$. (B) Images every $5 \mathrm{~min}$ (time in upper left corner) from the Aloft-Conn camera provide an estimate of local sea ice coverage $(\times / 10$ in upper right corner). 


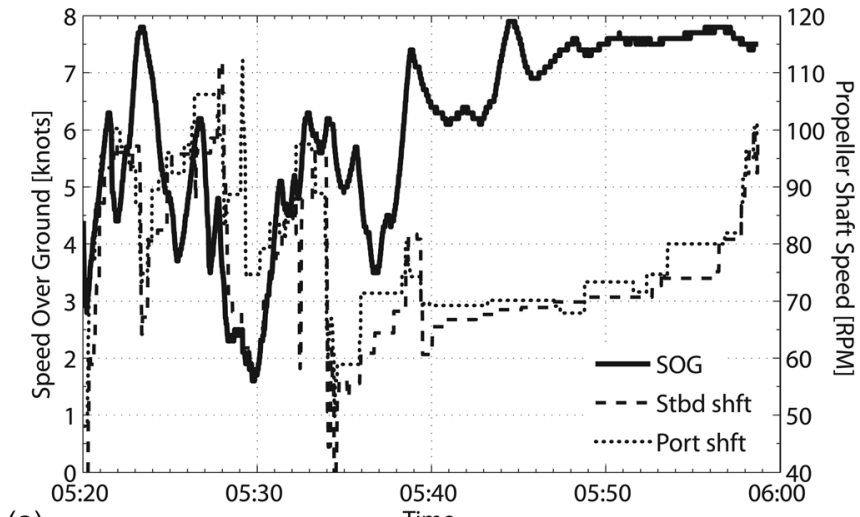

(a)

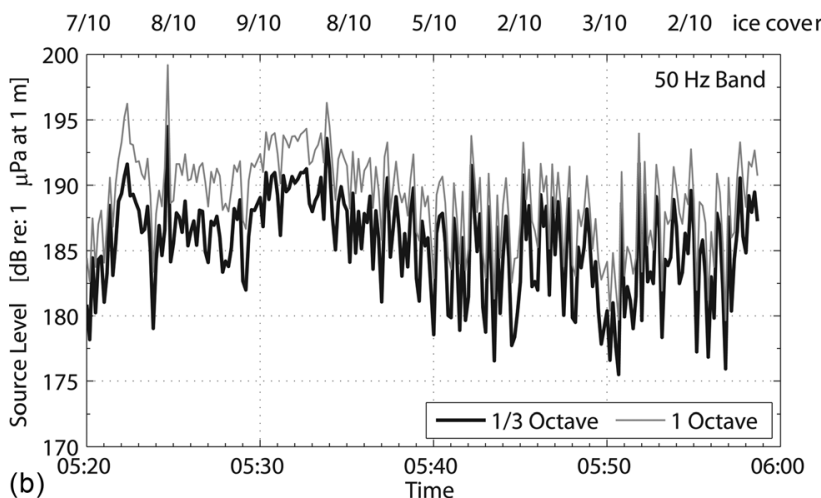

FIG. 4. During August 27 transit: (A) vessel speed-over-ground (solid) and propeller shaft rotational speeds (starboard $=$ dashed; port $=$ dotted). $(\mathrm{B})$ Source level estimates (dB re: $1 \mu \mathrm{Pa}$ at $1 \mathrm{~m})$ centered around $55.6 \mathrm{~Hz}(49$ $62 \mathrm{~Hz}$ band) for $1 / 3$ octave band and $56.6 \mathrm{~Hz}(40-80 \mathrm{~Hz}$ band) for 1-octave band. Sea ice coverage estimates are shown at 5-min intervals along the top of the graph.

Because actual calibration values may vary slightly in manufacturing, several sonobuoys were saved from the same manufacturing batches as those used in the field. Postexperiment calibrations of the hydrophones were conducted
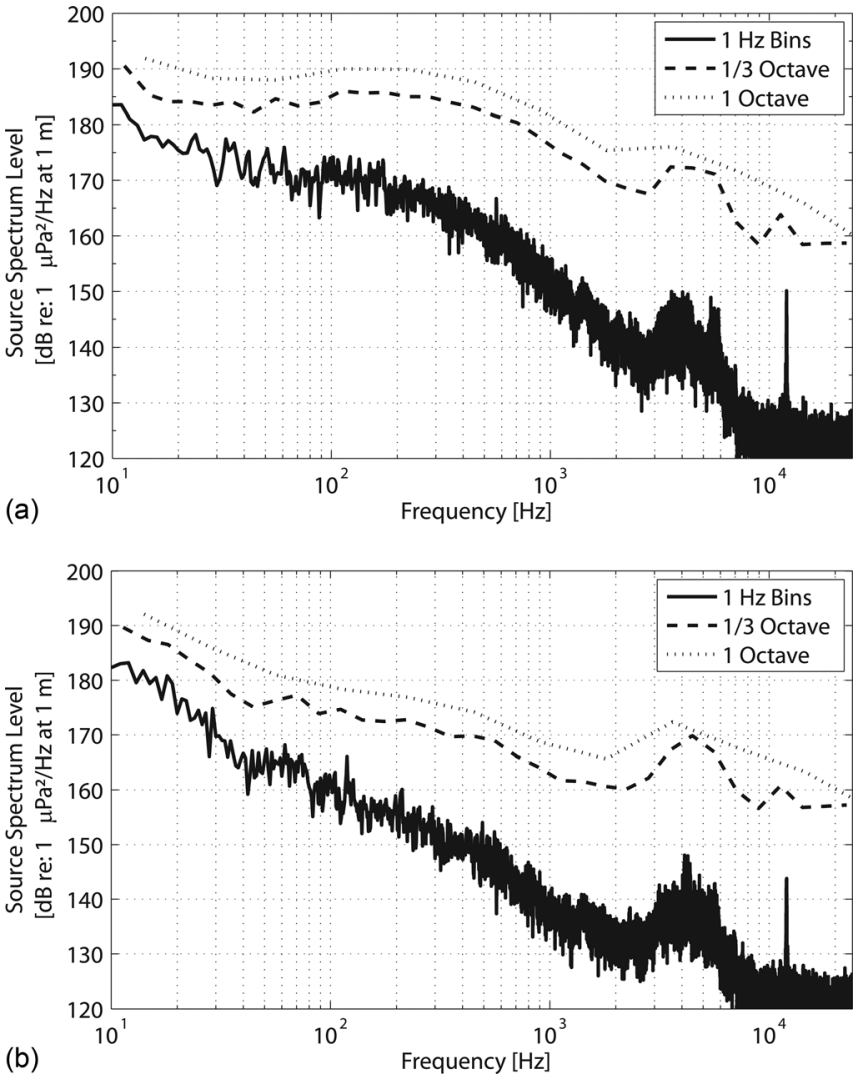

FIG. 5. During August 27 transit: (A) estimated source level of Healy transiting in 8/10's ice cover at 05:26:30; range to the sonobuoy was approximately $2 \mathrm{~km}$. (B) Estimated source level of Healy transiting in 3/10's ice cover at 05:51:20; range to the sonobuoy was approximately $4 \mathrm{~km}$.

at the Transducer Evaluation Center (TRANSDEC) facility in San Diego, CA.

Calibration runs were performed at a depth of $6 \mathrm{~m}$ to measure the received sensitivity of each sonobuoy in
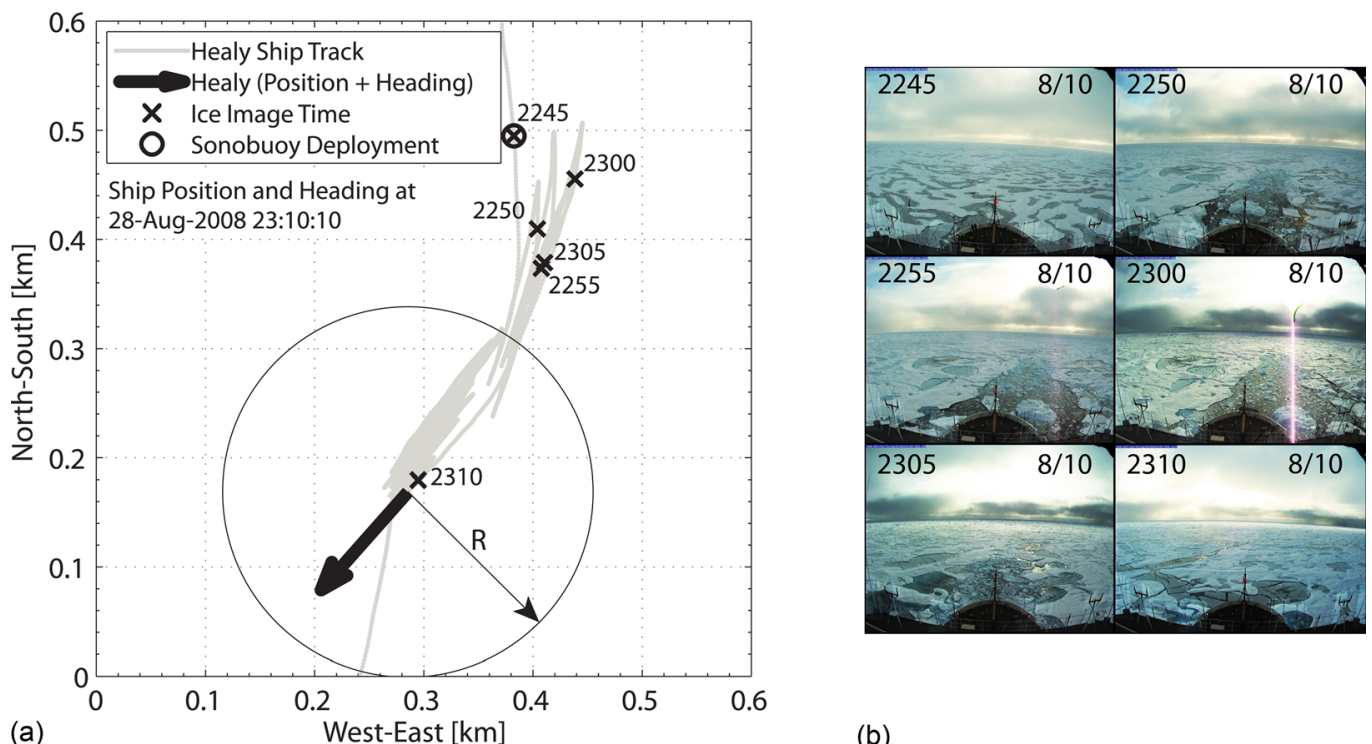

(b)

FIG. 6. (Color online) During backing-and-ramming operations on August 28, 2008: (A) ship track (gray line) relative to the sonobuoy deployment (small black circle), range estimate to the sonobuoy (large circle), as well as the position and heading of Healy at 23:10:10 (arrow). Coordinate system origin is at $82^{\circ} 3.73^{\prime} \mathrm{N}, 142^{\circ} 28.40^{\prime} \mathrm{W}$. (B) Images every 5 minutes (time in upper left corner) from the Aloft-Conn camera estimate local sea ice coverage $(\times / 10$ in upper right corner). 
response to calibrated source transducers transmitting different frequency tones from $10 \mathrm{~Hz}$ to $30 \mathrm{kHz}$ at a distance of 2-10 $\mathrm{m}$. An expected transfer function or frequency response calibration was computed based on the sensitivity of the transducer elements in addition to the signal conditioning provided by the amplifiers in the hydrophone, radio, and A/D converter. There was an uncertainty of $\pm 1-2 \mathrm{~dB}$ associated with the calculated transfer function compared to the measured calibration response. Once the transfer function was applied to the raw data, measurements were reported as received pressure levels (dB re: $1 \mu \mathrm{Pa} \mathrm{rms).}$

\section{Signal processing}

The MatLaв-based (The MathWorks Inc., Natick, MA) software package TRITON (Wiggins and Hildebrand, 2007) was used for first-level signal processing to determine whether data were clipped or not of suitable quality due to poor VHF radio transmission. In general, if the hydrophone was within $1 \mathrm{~km}$ of Healy, the data were clipped and not used. When the sonobuoy was greater than $5 \mathrm{~km}$ from Healy, it became difficult for the radio receiver to acquire continuous data with good quality.

Spectral measurements are calculated from 1 or $5 \mathrm{~s} \mathrm{sam-}$ ples of continuous data with no overlap between each spectral average using the Goertzel algorithm to calculate power spectral densities from discrete-time fast Fourier transforms (FFTs). All spectra were processed with a Hanning window and 48000 -point FFT length, yielding $1 \mathrm{~Hz}$ frequency bins. For comparative analysis, spectral measurements are reported using $1 \mathrm{~Hz}$ bins as well as $1 / 3$ and 1 octave bands based on a starting frequency of $10 \mathrm{~Hz}$. After correcting for transmission loss, measurements are reported as source levels at $1 \mathrm{~m}$.

\section{E. Source/receiver range and azimuth}

To estimate source levels from measured received levels, range estimation from the ship to the sonobuoy was required to calculate transmission losses. In correcting for transmission loss, a range dependent spreading loss of $20 \log _{10}(R)$ was assumed, where $R$ is the source/receiver slant range in meters. Ray-trace refraction and reflection analysis was used to estimate the distance between Healy's sonar and the sonobuoy hydrophone. The time difference between arrivals resulting from direct path and first bottom reflection of the ship's $12 \mathrm{kHz}$ echo sounder were measured in the sonobuoy acoustic data. These direct-path/first-reflection time differences were converted to ranges between the ship and the sonobuoy through an iterative procedure in which an acoustic propagation model, incorporating the measured sound speed profile, local water depth, and depth of the sonobuoy hydrophone, were adjusted until the observed time difference was matched (Fig. 2 and supplementary Figs. 1 and 2). ${ }^{1}$ Over the relatively short propagation ranges used for this study $(1-5 \mathrm{~km})$, we found that $20 \log _{10}(R)$ was a good approximation for the transmission loss. The geometry and range of our measurements are such that direct path propagation is all but guaranteed, and sound scattering or reradiating from the water-ice interface is not thought to contribute meaningfully to our measurements.
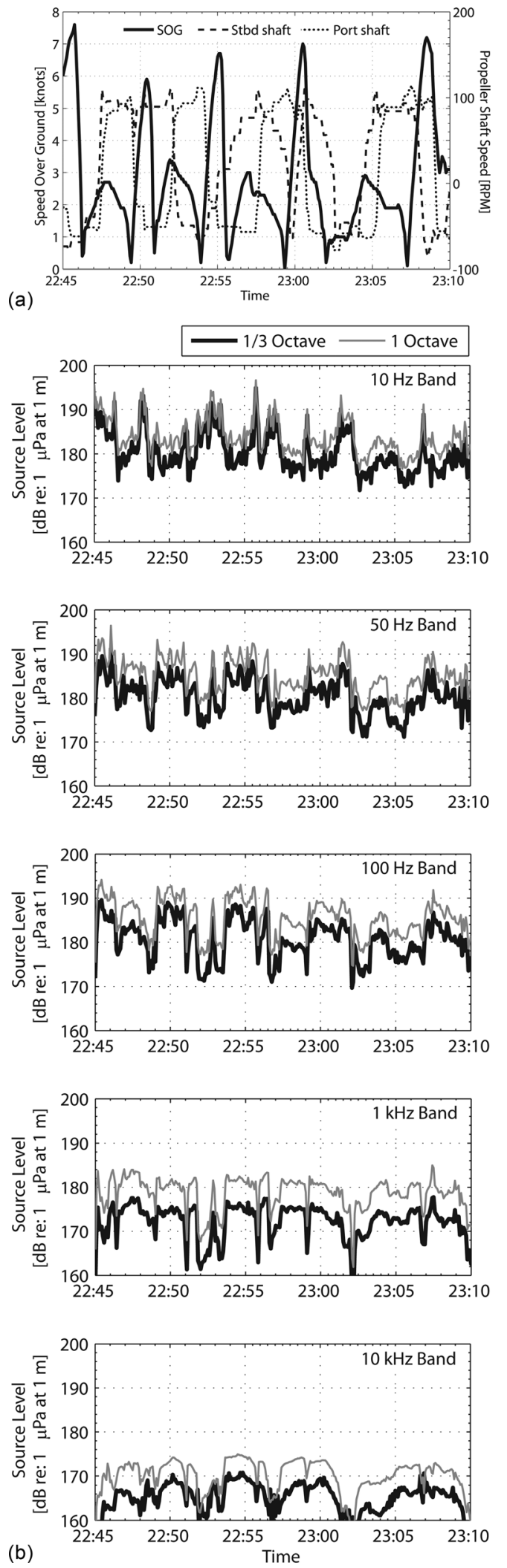

FIG. 7. During August 28 backing-and-ramming operations: (A) vessel speed-over-ground (solid) and propeller shaft rotational speed (starboard = dashed; port $=$ dotted). (B) Source level estimates $(\mathrm{dB}$ re: $1 \mu \mathrm{Pa}$ at $1 \mathrm{~m})$ centered around $11.3 \mathrm{~Hz}(10-13 \mathrm{~Hz}), 55.6 \mathrm{~Hz}(49-62 \mathrm{~Hz}), 111 \mathrm{~Hz}(98-123 \mathrm{~Hz})$, $1.12 \mathrm{kHz}(0.985-1.24 \mathrm{kHz})$, and $11.3 \mathrm{kHz}(9.93-12.5 \mathrm{kHz})$ for $1 / 3$ octave bands, respectively. Spectral estimates for full octave bands are centered around $14.1 \mathrm{~Hz}(10-20 \mathrm{~Hz}), 56.6 \mathrm{~Hz} \quad(40-80 \mathrm{~Hz}), 113 \mathrm{~Hz} \quad(80-160 \mathrm{~Hz})$, $0.905 \mathrm{kHz}(0.640-1.28 \mathrm{kHz})$, and $7.24 \mathrm{kHz}(5.12-10.24 \mathrm{kHz})$, respectively. The ship was consistently in $8 / 10$ 's ice cover. 
Because the sonobuoys drifted due to pack ice movements, winds, and ocean currents, the relative bearing of the sonobuoy to the ship, and hence the azimuthal aspect of the ship that was measured at any instant is not known. Therefore azimuthal variations in the ship's radiated noise are not considered in the analysis. When directionality in shipgenerated noise due to propeller cavitation has been previously observed, it is described as a dipole with smaller amplitudes on the ship's bow and stern (Arveson and Vendittis, 2000). Limited visual observations of the sonobuoy deployments indicated that the sonobuoy likely remained abaft the beam when Healy was transiting. This may lead to slightly decreased measurements from those produced in accordance with the ANSI standard (ANSI, 2009), which specifies measurements within $30^{\circ}$ of the ship's beam.

\section{F. Ancillary data}

Healy is equipped with a ship-wide computerized data logging system that records and stores data from the navigation, oceanographic, engineering, and communications systems. Several of these ancillary measurements were used for analysis, including Healy's position, heading, and speed over ground, as well as environmental information such as the local sea ice coverage, which was estimated from time-lapse images to the nearest $10 \%$. The engineering data provided the time along with corresponding port and starboard propeller shaft speeds averaged from the cycloconverter readings and converted from percentages to pure shaft rpm's.

\section{RESULTS}

Several transient and continuous acoustic events were selected as case studies for analysis that most accurately reflect Healy's noise signature. Propulsion modes include transit in varying pack ice conditions, backing-and-ramming maneuvers, and dynamic positioning.

\section{A. Transit in variable ice cover}

During August 27, Healy transited from nearly complete sea ice cover to an open-water polynya (Fig. 3 and supplementary Fig. 1). Healy's transition from ice-breaking to open water is evident at approximately 05:37 when propeller shaft rpm's decreased and speed over ground (SOG) increased as the resistance to movement abated in open water [Fig. 4(A)]. A time series of source level estimates centered near $50 \mathrm{~Hz}$ shows a decrease in mean level during the transition from ice-breaking to open water [at 05:37 in Fig. 4(B)]. Moreover, large amplitude noise peaks [e.g., 05:22 and 05:24 in Fig. 4(B)] are reduced when the ship is operating in open water.

A comparison of source spectrum levels while Healy is transiting through 8/10's and 3/10's ice cover is shown in Figs. 5(A) and 5(B), respectively. At $10 \mathrm{~Hz}$, both source spectra exhibit similar levels of about $182-183 \mathrm{~dB}$ re: $1 \mu \mathrm{Pa}^{2} / \mathrm{Hz}$ at $1 \mathrm{~m}$ ( $1 \mathrm{~Hz}$ bins). Above $20 \mathrm{~Hz}$, however, there is a $10 \mathrm{~dB}$ difference on average between the two source spectra. In icecovered waters, the full octave band remains approximately flat between 100 and $300 \mathrm{~Hz}$ [Fig. 5(A)], while in open water the full octave band slopes steadily downward with frequency up to $2 \mathrm{kHz}$ [Fig. 5(B)]. In the $1 \mathrm{~Hz}$ bin spectra, underwater noise levels are higher by as much as $15 \mathrm{~dB}$ between $200 \mathrm{~Hz}$ and $2 \mathrm{kHz}$ during moderate ice-breaking conditions when compared to open-water transit. In both spectra, elevated levels between 3 and $5 \mathrm{kHz}$ are attributed to the acoustic chirp

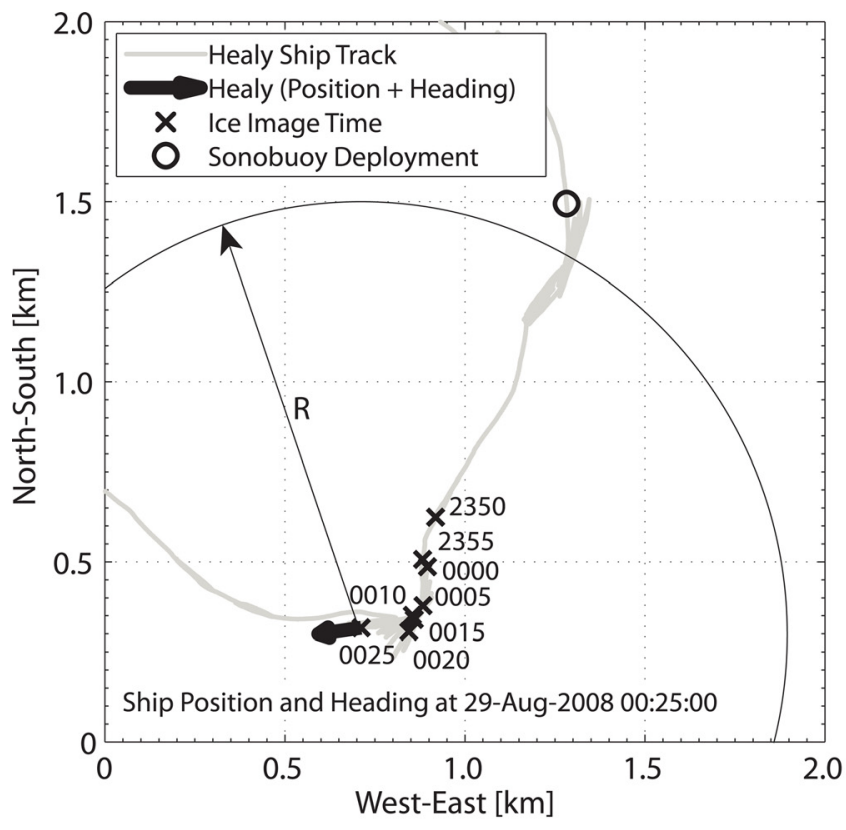

(a)

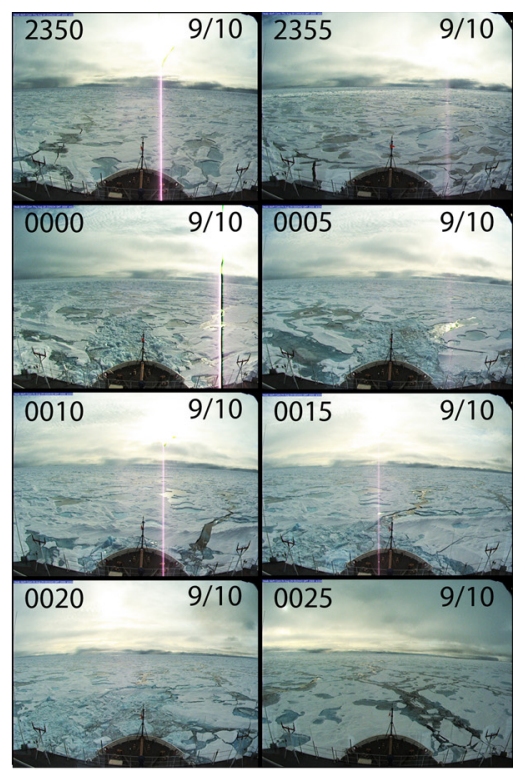

(b)

FIG. 8. (Color online) During backing-and-ramming on August 28-29, 2008: (A) ship track (gray line) relative to the sonobuoy deployment (small black circle), range estimate to sonobuoy (large circle) as well as the position and heading of Healy at 00:25:00 (arrow). Coordinate system origin is at $82^{\circ} 3.27^{\prime} \mathrm{N}$, $142^{\circ} 30.27^{\prime} \mathrm{W}$. (B) Images every $5 \mathrm{~min}$ (time in upper left corner) from the Aloft-Conn camera estimate local sea ice coverage $(\times / 10$ in upper right corner). 
from the ship's Knudsen sub-bottom profiler. Narrowband peaks at $12 \mathrm{kHz}$ are due to the ping produced by Healy's SeaBeam 2102 multibeam echo sounder.

\section{B. Backing-and-ramming in full ice cover}

On August 28, a sonobuoy recording was made during multiple backing-and-ramming maneuvers [Fig. 6(A) and supplementary Fig. 2]. Twenty-five minutes of the recording were analyzed while the ship was in consistent 8/10's ice cover [Fig. 6(B)]. The port and starboard screws were not operated simultaneously in the same direction as the ship attempted to change its heading in the ice [Fig. 7(A)]. The non-synchronous operation of the two screws complicated attempts to correlate rpm's with source levels during this recording. Positive (i.e., forward) rpm movement and subsequent increases in SOG characterize ramming. Negative (i.e., sternward) rpm movement and subsequent increases in SOG characterize backing. The ship reached 6-7 kn $(3.1-3.6 \mathrm{~m} / \mathrm{s})$ forward speed before progress was halted by the pack ice. Reversing the direction of the screws, the ship backed up, reaching speeds around $3 \mathrm{kn}(1.5 \mathrm{~m} / \mathrm{s})$ before attempting to make forward progress again. This alteration in SOG indicates that the ship was breaking heavy ice while making forward progress into the hole created by the previous ram.

The modulation in SOG over the course of the recording corresponds with the source level time series shown in Fig. 7(B). Healy's noise signature was examined in frequency bands by orders of magnitude (i.e., centered near $10^{1}, 10^{2}$, $10^{3}$, and $10^{4} \mathrm{~Hz}$ ), including one centered near $50 \mathrm{~Hz}$, to see if the distribution of source levels was frequency dependent. For the time series centered near 10,50 , and $100 \mathrm{~Hz}$, source levels increased $10 \mathrm{~dB}$ in several instances, correlating with negative rpm's of one or both of the ship's propeller shafts. The effect is shown to a lesser extent in frequency bands centered near 1 and $10 \mathrm{kHz}$. The highest estimated source level reached during this recording was about $195 \mathrm{~dB}$ re: $1 \mu \mathrm{Pa}$ at $1 \mathrm{~m}$, in full octave bands at 10 and $50 \mathrm{~Hz}$.

Another recording was made during several hours of Healy backing-and-ramming in heavy ice cover during $\mathrm{Au}-$ gust 28-29 [Fig. 8(A)]. Thirty-five minutes were analyzed, while the ship was in 9/10's ice cover [Fig. 8(B)]. For the spectral time series centered near 50, 100, and $1000 \mathrm{~Hz}$, source levels quickly increased $10-15 \mathrm{~dB}$ in several instances, again correlating with rapid deceleration of the ship from forward movements and sternward operation of the screws (Fig. 9). However, in this case, the same effect also is seen with the higher frequency band centered near $1 \mathrm{kHz}$. The highest source level reached during this recording was about $200 \mathrm{~dB}$ re: $1 \mu \mathrm{Pa}$ at $1 \mathrm{~m}$, in full octave bands at 50 and $100 \mathrm{~Hz}$.

When the ship is engaged in backing-and-ramming maneuvers, the largest modulation in Healy's noise signature results from severe cavitation of the propellers while operating astern. In bands centered near 10,50 , and $100 \mathrm{~Hz}$, source levels were shown to increase $5-15 \mathrm{~dB}$ during backing-andramming maneuvers. Specifically, noise levels increased $10-15 \mathrm{~dB}$ in the $50 \mathrm{~Hz}$ and $100 \mathrm{~Hz}$ bands while operating astern propulsion as compared to operating forward propulsion while breaking ice.

\section{Dynamic positioning in full ice cover}

On August 31, a recording was made during deep sea dredging operations [Fig. 10(A)]. Twenty-five minutes of data were analyzed while the ship was using its bow thruster
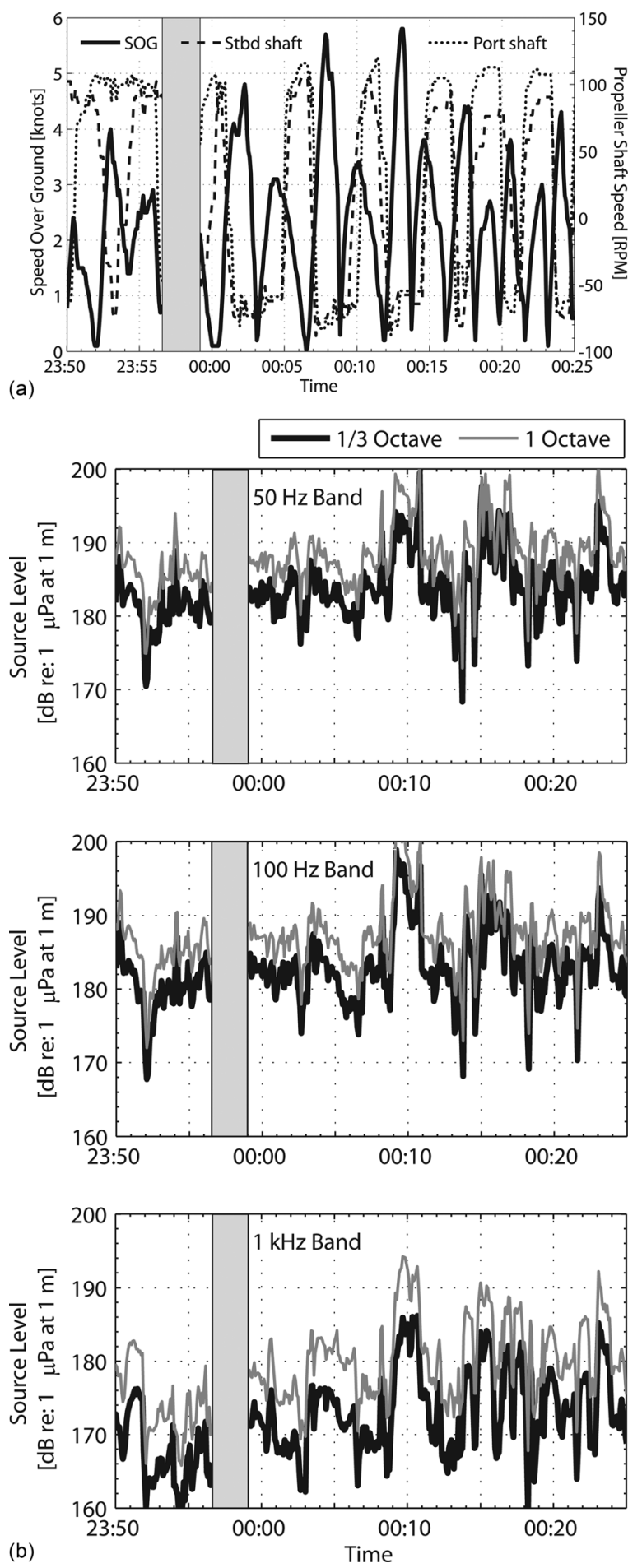

FIG. 9. During backing-and-ramming on August 28-29: (A) vessel speedover-ground (solid) and propeller shaft rotational speed (starboard = dashed; port $=$ dotted). (B) Source level estimates $(\mathrm{dB}$ re: $1 \mu \mathrm{Pa}$ at $1 \mathrm{~m})$ centered around $55.6 \mathrm{~Hz}(49-62 \mathrm{~Hz}), 111 \mathrm{~Hz}(98-123 \mathrm{~Hz})$, and $1.12 \mathrm{kHz}(0.985-$ $1.24 \mathrm{kHz}$ ) for $1 / 3$ octave bands, respectively. Spectral estimates for full octave bands are centered around $56.6 \mathrm{~Hz}(40-80 \mathrm{~Hz}$ band), $113 \mathrm{~Hz}(80-$ $160 \mathrm{~Hz}$ band), and $0.905 \mathrm{kHz}(0.640-1.28 \mathrm{kHz}$ band), respectively (gray section indicates loss of acoustic data). The ship was in consistent 9/10's ice cover. 


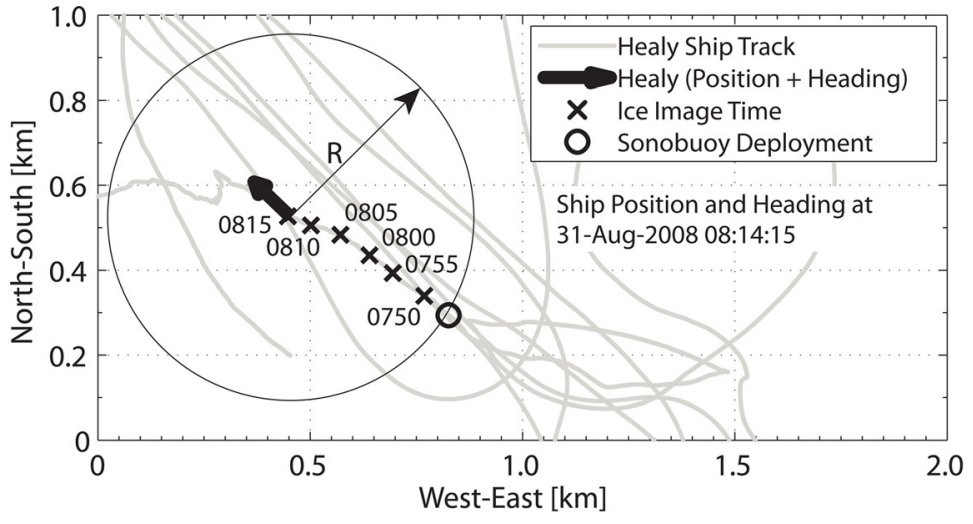

(a)

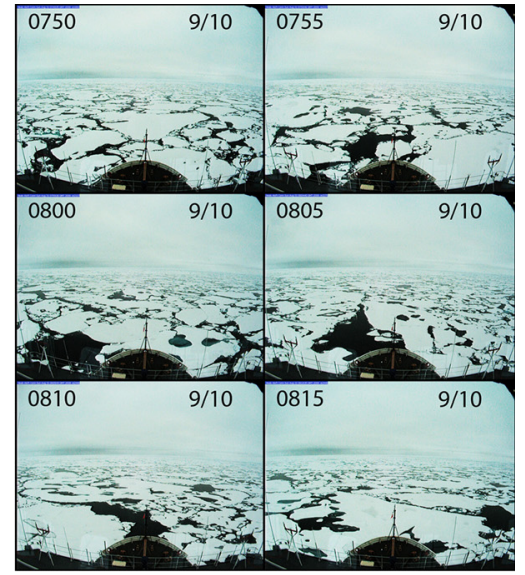

(b)

FIG. 10. (Color online) During deep-sea dredging operations on August 31, 2008: (A) ship track (gray line) relative to the sonobuoy deployment (small black circle), sonobuoy range estimate (large circle) as well as the position and heading of Healy (arrow). Coordinate system origin is at $81^{\circ} 24.14^{\prime} \mathrm{N}, 151^{\circ} 58.40^{\prime} \mathrm{W}$. (B) Images every $5 \mathrm{~min}$ (time in upper left corner) from the Aloft-Conn camera estimate sea ice coverage $(\times / 10$ in upper right corner).

and propellers in 9/10's ice cover [Fig. 10(B)]. Healy never exceeded $1 \mathrm{kn}(0.5 \mathrm{~m} / \mathrm{s})$ during this time, achieved by intermittingly applying short bursts to the throttle. These data allow characterization of Healy's source levels while using its bow thruster to operate in a dynamic positioning mode. The ship was dragging the dredge up the seafloor slope, moving variably between 0.3 and $1.0 \mathrm{kn}(0.2-0.5 \mathrm{~m} / \mathrm{s})$. The propeller blades were below cavitation inception so this contribution to the sound field was absent.

A source level spectrum (Fig. 11) represents radiated noise while operating the bow thruster in heavy ice cover. The bow thruster contributes significant narrowband spectral peaks at 30 and $55 \mathrm{~Hz}$, reaching source levels of $193 \mathrm{~dB}$ re: $1 \mu \mathrm{Pa}$ at $1 \mathrm{~m}$ in the full octave band. There are several harmonics associated with the $55 \mathrm{~Hz}$ peak at $110 \mathrm{~Hz}, 165 \mathrm{~Hz}$, etc. Above $200 \mathrm{~Hz}$, source levels drop to values similar to those seen in the open-water source spectra [Fig. 5(B)] except for frequencies greater than $10 \mathrm{kHz}$ where a noise peak of $178 \mathrm{~dB}$ re: $1 \mu \mathrm{Pa}$ at $1 \mathrm{~m}$ is seen in the full octave band.

\section{DISCUSSION}

\section{A. Variability in icebreaker source levels}

Based on the ancillary data available for this study, individual propeller shaft speed (rpm) is a key parameter that can be related to the ship's acoustic power output as well as sea ice conditions. SOG can be a proxy for moving through ice but does not necessarily correlate with higher noise levels. For instance, there is no strong correlation between higher noise levels and movement astern. The sources of higher noise levels are correlated with rpm in the astern direction. When the ship attempts to turn by using opposing screws, higher noise levels do correlate with operation of one screw forward and the other in reverse. Figure 12 shows Healy's source levels, averaged from the recordings made between August 27 and 29. This plot shows that astern propulsion contributes most to high noise levels and that operation of the screws in opposing directions also contributes. Operating ahead, even when breaking ice, does not typically produce high noise conditions.
There are two scenarios in which noise levels are noticeably higher - the first is when screws are operated in opposing directions; the second is during backing and ramming when the screws are operated astern, particularly when the ship begins to impact the ice. Higher noise levels correlate positively when both screws are operated astern together. In addition, it seems that the SOG in the astern direction peaks and then starts to slow and that the higher noise levels begin when the slowing occurs but with no change in rpm. This implies that the ship is beginning to impact the ice behind it and may be pulling ice debris into the propellers.

The highest source levels occur during backing-andramming, reaching $190-200 \mathrm{~dB}$ re: $1 \mu \mathrm{Pa}$ at $1 \mathrm{~m}$ (full octave band at $10,50,100 \mathrm{~Hz}$ ), correlating with sternward operation of the screws during backing maneuvers (Figs. 7 and 9). Cosens and Dueck (1993) also noted in their study of icebreaker noise that the highest levels occurred when the icebreaker was going into reverse. During backing and ramming, source levels increase when the ship quickly transitions from reverse to forward propulsion.

\section{B. Propeller cavitation and other noise sources}

Cavitation of marine propellers from surface ships is the most prevalent source of underwater sound in the oceans

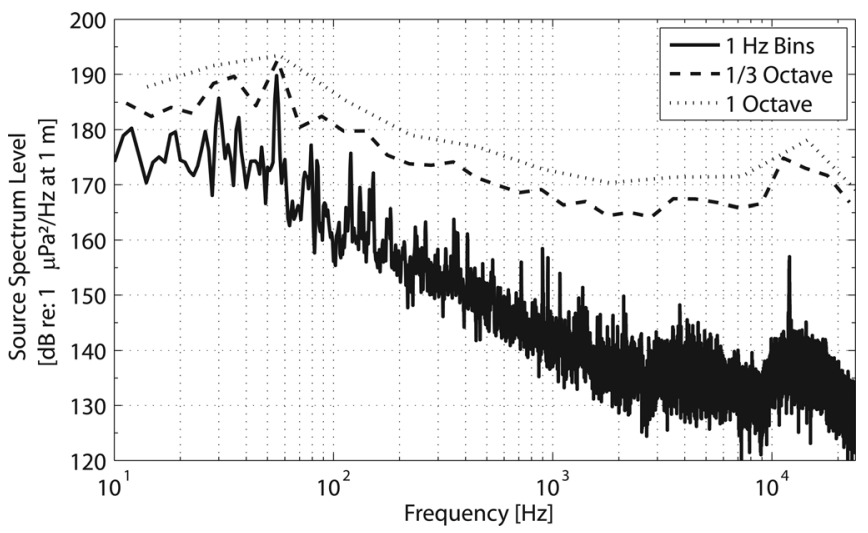

FIG. 11. Source level of Healy on August 31, while using its bow thruster in 9/10's ice cover; range to the sonobuoy was approximately $500 \mathrm{~m}$. 
(Ross, 1976). Depending upon the operating cavitation parameter, each propeller blade produces cavitation for a short period when their angles of attack are less than the nominal advance ratio. The resultant burst of cavitation noise is brief. Because one blade invariably cavitates sooner than the others, the bursts first occur once per revolution. As the other blades begin cavitating, the noise bursts become more frequent, finally occurring at blade rate - the number of blades multiplied by the rotational frequency.

Cavitation inception usually depends more on the ship wake than on the design of the propeller. For severe wakes, stall is likely to occur when the propeller blade passes behind the stern post, or so-called "shadow zone" (Ross, 1976). Icebreakers are unique in this regard as they invariably encounter a situation during backing and ramming where the ship's propeller shafts are rotating at nearly full speed, yet the SOG of the vessel falls due to increased resistance from pack ice. At this moment, there is not only stagnant fluid flow in the shadow zone but everywhere around the propeller. The drop in dynamic pressure of flow velocity around the propeller blades causes increased cavitation inception simultaneously for all the propeller blades, resulting in the highest noise levels produced by the icebreaker.

Other noise sources are propulsion machinery and diesel generators. Diesel-electric drives-like the propulsion system found on Healy-employ four-stroke medium-speed diesels that are quite noisy compared to slow-speed directdrive engines and produce multiple tones attributed to piston slap. These four-stroke medium speed diesels can radiate as many as 100 harmonics of their rotational frequencies (Ross, 1976). This noise source usually becomes important when a ship is operating at slow speeds, for example, when

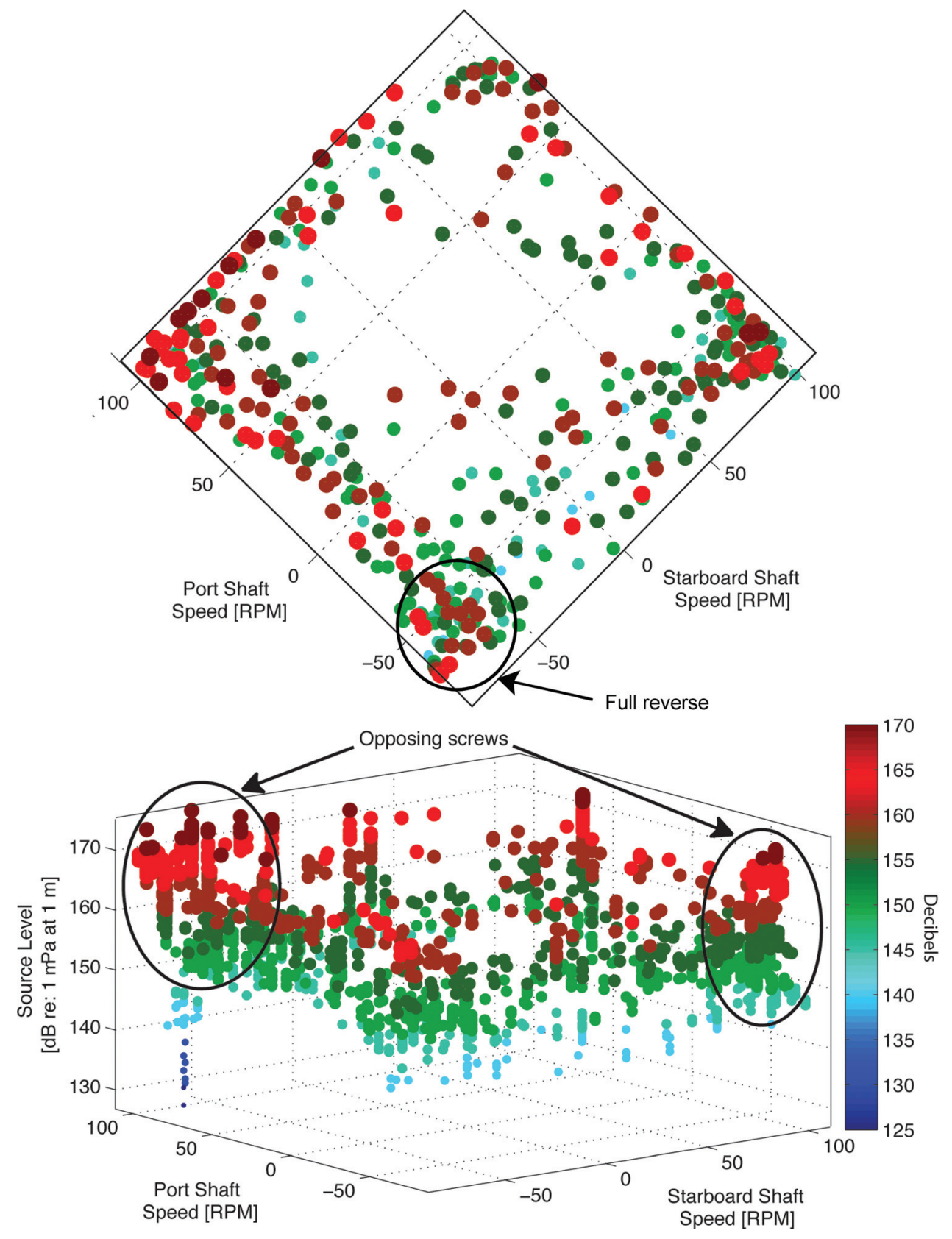

FIG. 12. Source levels averaged from the August 27-29 recordings, together with the ship's port and starboard propeller shaft speeds (RPM) as (A) two-dimensional plot and (B) three-dimensional plot. The point-size increases and the color of each point changes (scale bar on right) in $5 \mathrm{~dB}$ increments. The ship frequently transitioned from reverse to forward motion, and the propeller shaft rotation quickly changed direction. 
icebreakers maneuver through substantially thick, icecovered waters. For this reason, Healy's engines are located on the main deck to reduce noise for the sonar systems.

Ross (1976) has suggested that the total noise radiated by a surface ship may be estimated from

$\mathrm{SPL}=126+15 \log (\mathrm{HP})$ in $\mathrm{dB}$ re: $1 \mu \mathrm{Pa}$ at $1 \mathrm{~m}$, where HP $=$ horsepower. As an example, if Healy's maximum shaft horsepower is $30000 \mathrm{HP}$ at $130 \mathrm{rpm}$, then the source level would be about $193 \mathrm{~dB}$ re: $1 \mu \mathrm{Pa}$ at $1 \mathrm{~m}$, which is similar to those peak values presented here for low frequencies during low SOG when operating in pack ice.

\section{CONCLUSIONS}

The presence of sea ice represents a significant obstacle to vessels operating anywhere in polar waters, and requires specially constructed ships and navigational skills (Brigham, 2000). The thinning Arctic ice pack is allowing for longer seasons of navigation for icebreakers and other polar-class vessels. Increases in vessel traffic around the Arctic Ocean may result in an increase in the risk of disturbance from ship noise on migrating and foraging whales as well as other marine animals. In an effort to better predict these risks, protocols for the measurement of radiated ship noise (ANSI, 2009) should be expanded specifically to icebreakers operating in polar regions with ice-covered waters. Combined with a more thorough understanding of under-ice acoustic propagation, standard measurements such as these will allow better management of our shared Arctic resources.

\section{ACKNOWLEDGMENTS}

Support for the field program was provided by the Center for Coastal and Ocean Mapping/Joint Hydrographic Center (CCOM/JHC) and the U.S. Coast Guard. The authors would like to thank Jon Childs of the U.S. Geological Survey for providing funding and support for this work. We also thank Larry Mayer of CCOM/JHC, who provided field support and allowed us to conduct acoustic measurements opportunistically during the HLY-0805 cruise; Philip McGillivary of the U.S. Coast Guard, who encouraged us to initiate the study; the crew of USCGC Healy, especially engineering officers LCDR Doug Petrusa and ENS Lisa Myatt, who provided engineering data recorded during our acoustic measurements; and Don Ross who provided valuable insight and guidance on underwater noise research. Funding for this work has been provided by the U.S. Interagency Extended Continental Shelf Task Force, consisting of representatives from the Department of State, NOAA, Department of Interior (USGS, MMS), U.S. Coast Guard, National Science Foundation, and Arctic Research Commission, among others. Neither the Extended Continental Task Force, nor individual agencies endorse the conclusions of this study.

${ }^{1}$ See supplementary material at http://dx.doi.org/10.1121/1.4790356 for supplemental Figs. 1 and 2.

ANSI (2009). S12.64, American National Standard, Quantities and Procedures for Description and Measurement of Underwater Sound from Ships. Part 1. General Requirements (Acoustical Society of America, New York).

Arctic Council (2009). Arctic Marine Shipping Assessment 2009 Report, 2nd printing (Arctic Council, Tromsø, Norway), p. 194.

Arveson, P. T., and Vendittis, D. J. (2000). "Radiated noise characteristics of a modern cargo ship," J. Acoust. Soc. Am. 107(1), 118-129.

Berkson, J., and DuPree, G. (1998). "USCGC Healy: The United States' new polar research icebreaking vessel," www.uscg.mil/history/webcutters/ HealyNarrative.pdf (Last viewed January 27, 2010).

Brigham, L. W. (2000). The Emerging International Polar Navigation Code: Bi-Polar Relevance? (Cambridge University Press, Cambridge, UK), p. 221-243.

Cosens, S. E., and Dueck, L. P. (1993). "Icebreaker noise in Lancaster Sound, N.W.T., Canada: Implications for marine mammal behavior," Marine Mammal Sci. 9(3), 285-300.

Etter, P. C. (2003). Underwater Acoustic Modeling and Simulation (Spon Press, New York), p. 384.

Jakobsson, M., Macnab, R., Mayer, L., Anderson, R., Edwards, M., Hatzky, J., Schenke, H. W., and Johnson, P. (2008). "An improved bathymetric portrayal of the Arctic Ocean: Implications for ocean modeling and geological, geophysical and oceanographic analyses," Geophys. Res. Lett. 35, L07602.

Jensen, Ø. (2007). "The IMO guidelines for ships operating in arctic icecovered waters: From voluntary to mandatory tool for navigation safety and environmental protection," FNI-rapport 2/2007 (The Fridtjof Nansen Institute, Lysaker, Norway), p. 32.

Mayer, L. A., and Armstrong, A. A. (2008). USCGC Icebreaker Healy (WAGB-20) U.S. Law of the Sea Cruise to Map the Foot of the Slope and 2500-m Isobath of the US Arctic Ocean Margin (Center for Coastal and Ocean Mapping/Joint Hydrographic Center, University of New Hampshire, Durham. NH), p. 179.

Mellinger, D. K. (2001). Ishmael 1.0 User's Guide. NOAA Technical Report OAR-PMEL-120 (NOAA Pacific Marine Environmental Laboratory, Seattle, WA), p. 30.

Milne, A. R., and Ganton, J. H. (1964). "Ambient noise under Arctic-Sea ice,” J. Acoust. Soc. Am. 36(5), 855-863.

O'Rourke, R. (2012). Coast Guard Polar Icebreaker Modernization: Background and Issues for Congress (Congressional Research Service, Washington, DC), p. 4-6.

Ross, D. (1976). Mechanics of Underwater Noise (Pergamon, New York), p. 375.

Wiggins, S. M., and Hildebrand, J. A. (2007). "High-Frequency Acoustic Recording Package (HARP) for broad-band, long-term marine mammal monitoring," in International Symposium on Underwater Technology 2007 and International Workshop on Scientific Use of Submarine Cables and Related Technologies 2007, Tokyo, Japan, Institute of Electrical and Electronics Engineers. 